\title{
Sisters in sustainability: municipal partnerships for social, environmental, and economic growth
}

\author{
Dustin McLarty • Nora Davis • Joshua Gellers • \\ Nasrin Nasrollahi • Erik Altenbernd
}

Received: 20 August 2013/ Accepted: 12 February 2014/Published online: 8 March 2014

(C) The Author(s) 2014. This article is published with open access at Springerlink.com

\begin{abstract}
While debates about sustainable development tend to focus on national- and international-scale problems, sustainability programs and research generally focus on the regional, county, municipal, or even household level. Less research has focused on evaluating the benefits of pairing two cities (i.e., sister city partnerships) with different needs and capabilities to jointly enhance the potential for sustainable practices between the cities. Given shrinking state and federal budgets and the nascent national climate policy, how might US cities use existing resources to achieve greater levels of sustainability? This paper presents a new
\end{abstract}

Handled by Victor Savage, National University of Singapore, Singapore.

D. McLarty $(\square) \cdot$ N. Davis · J. Gellers · N. Nasrollahi .

E. Altenbernd

Environment Institute, University of California Irvine, Irvine,

CA 92697, USA

e-mail: dmclarty@uci.edu

D. McLarty

Department of Mechanical and Aerospace Engineering,

University of California Irvine, Irvine, CA 92697, USA

N. Davis

Department of Social Ecology, University of California Irvine, Irvine, CA 92697, USA

J. Gellers

Department of Political Science, University of California Irvine, Irvine, CA 92697, USA

\section{N. Nasrollahi}

Department of Civil and Environmental Engineering, University of California Irvine, Irvine, CA 92697, USA

E. Altenbernd

Department of History, University of California Irvine, Irvine, CA 92697, USA data-driven mathematical tool-the partnership assessment for intra-regional sustainability - that city planners can use to explore the prospects for improving sustainability practices by leveraging existing resources and establishing synergistic partnerships with neighboring cities. The efficacy of the tool is assessed through the presentation of a Southern California case study and the results of a psychological survey of Southern California residents. Results indicate that cities of different size and scale would benefit from synergistic sustainability programs that pool the resources and needs of both cities. The paper concludes with a discussion of potential societal implications, methodological issues, and barriers to implementation.

Keywords Sustainability $\cdot$ Cities $\cdot$ Metrics .

Partnerships · Transdisciplinary $\cdot$ Local

\section{Introduction}

The challenges of social, environmental, and economic sustainability can seem insurmountable when examined at the global scale, but progress toward sustainable development can occur city by city, and region by region, through local initiatives and individual actions. However, rather than analyzing individual, one-off city programs, or regional and national scale frameworks, this paper demonstrates the benefits of local-level partnerships in two main ways: First, by utilizing a three pillar model of sustainability based on the environment, economy, and society, and second, by identifying latent or active intra-regional partnerships between municipalities that could address (and perhaps amplify and extend) mutual sustainability goals.

While municipal sustainability initiatives date back to the late 1990s (Dernbach 2000), cities continue to 
contribute significantly to global greenhouse gas emissions: $30-40 \%$ of global $\mathrm{CO}_{2}$ emissions originate within the geographic boundaries of cities (Satterthwaite 2008), and $78 \%$ of anthropogenic carbon emissions are attributable to urban areas when electricity and other goods imported into cities are considered (Stern 2007). Consequently, the expansion of urban population growth in cities throughout the world has placed great strains on the quality of the environment (i.e., air, water, and land) in these areas (Fan and Qi 2010). In the face of ever-increasing rates of urbanization throughout the world, many cities have sought to address these global problems by devising sustainability targets focused on local conservation policies and efforts. While these efforts might constitute a down payment on sustainable growth, they tend to be limited in scope and path dependent, and emphasize singular issues such as retrofitting buildings for higher energy efficiencies (e.g., lighting), incorporating solid waste management schemes, or expanding public transportation infrastructure (Bulkeley and Betsill 2003; Betsill 2001).

Equally problematic is the fact that local sustainability initiatives and policies can vary widely not only across regions and nations but even among neighboring communities. For instance, the Illinois cities of Urbana and Champaign, which are separate municipalities but together comprise a single geographically contiguous urban area, have vastly different sustainability programs. Urbana has developed its own farmers markets and residential energy reduction programs, while Champaign has focused primarily on integrating global economic sustainability programs (Kambuj 2013). Likewise, many regional-level sustainability collaborations such as SCAG (Southern California Area Governments) and MWCOG (Metropolitan Washington Council of Governments), which operate across municipal and county lines to set regional sustainability goals, rarely create binding commitments and often fail to effectively maximize the natural and human resources encompassed within their respective regions (Benfield 2012).

The interaction between different municipalities, agencies, and community groups working to utilize or preserve shared resources implicates the concept of the commons dilemma in nearly every regional or local sustainability initiative. Also known as the "Tragedy of the Commons," this concept is applicable anywhere as shared natural resources are depleted by self-interested individuals who are nevertheless aware that such depletions are contrary to the long-term interests of the larger social group to which they belong (Hardin 1968). Overcoming the commons dilemma and maximizing the utility of common resources through sharing require that decision makers see measurable reciprocities that accomplish a shared goal. The goal of our application was to highlight such reciprocities and improve local sustainability across five resource-intensive sectors.

Adapting the sister city phenomena

This study aims to address some of these local-scale, municipal-level sustainability challenges by repurposing the sister city model of civic cooperation. Such city-to-city connections first emerged in Europe between 1880 and 1900. After undergoing a period of expansion during the interwar years roughly (1920-1935), sister city programs were formally established by the hundreds all across Europe, North America, and the rest of the globe after World War II (WWII) (Ewen and Hebbert 2007). For much of this time, but especially since 1945 , sister city partnerships have aimed at fostering cultural and political exchange. The sister city phenomenon, which is known as "town twinning" in the United Kingdom and Europe, is typically defined by the establishment of social, cultural, and political ties between municipalities in separate nation-states. While a few instances of intranational twinning can be identified in Europe and Canada, the phenomenon has tended to be predominately international in nature (Zelinski 1991).

Despite some nineteenth- and early twentieth-century precedents, the current configuration of the sister city phenomenon-and its international orientation-is largely a product of the Cold War era. After World War II, a number of organizations and communities across Europe and the United States sought to establish closer sociocultural ties as a bulwark against future conflict and wars (Zelinski 1991; Clarke 2010). Within Europe, town twinning was generally developed without a universal definition or guideline. Großpietsch argues that the contemporary partnerships tend to evolve on a case-by-case basis as elected officials, and committed citizens from each municipality pursue their respective interests through their own particular interpretation of the partnership's objectives (Großpietsch 2010). In recent decades, the European Commission has funded town twinning with the dual objective of encouraging links between cities within established EU countries [i.e., those understood as "belonging to the same (European) civilization and destiny"] and empowering the authority of local governments rather than national bodies (Papagaroufali 2005). Related to the EU twinning initiative is the member organization Eurocities. Municipal cooperation within Eurocities is organized to reflect the three pillar sustainability model by addressing urban economic development, social inclusion, and climate change; however, the organization's primary focus is to serve as a political platform for 130 of Europe's largest cities. Whereas the objective of the EU twinning 
program was to connect city administrators and bring potential EU member states into closer compliance with the EU standards, the Eurocities organization works within existing EU states and more often than not encourages city councilors to adopt new laws and standards in order to secure government resources (Payre 2010). In this context, Großpietsch maintains that town twinning activities and exchanges create awareness and solidarity among European citizens which contribute to a collective European identity and the legitimization of the EU as political community (Großpietsch 2010).

Historically, sister city arrangements have been leading expressions of municipal internationalism (Clarke 2010) and have tended to possess three main characteristics. First, they are usually voluntarily in nature and express "strong locality considerations and local activism," sometimes in opposition to national foreign policy aims and frameworks (Zelinski 1991; Cremer et al. 2001; Vion 2002). Second, sister city relationships typically reflect "genuine reciprocity of effort and benefit, with neither community profiting at the expense of the other" (Zelinski 1991; Cremer et al. 2001). Lastly, sister city programs generally aim to foster and promote symbolic forms of economic exchange-that is, economic exchanges that can used to advance local cultural identities as well as promote more substantive exchanges of policy, knowledge, and expertise (Cremer et al. 2001; Großpietsch 2009; Jayne et al. 2011). Thus, the sister city model offers many insights into how different communities can realize mutual benefits from sharing not just particular goods and services, but institutional knowledge and expertise as well. We explore how this historic framework might be utilized to identify and achieve tangible, locally focused sustainability benefits.

In the United States, sister city programs are almost entirely international in orientation and practice. Our application repurposes the sister city model to focus on local rather than international partnerships and economic rather than symbolic economies. Our quantitative method of analysis, partnership assessment for intra-regional sustainability (PAIRS), is calibrated to provide city officials and managers with a means of identifying and establishing local, intra-national partnerships and mutually beneficial sustainability action plans. Most importantly, PAIRS is not a new metric by which to measure regional or municipal sustainability. Rather, it uses existing indicators and measurements to evaluate the potential impact of municipal partnerships. Leveraging existing sustainability efforts across municipal boundaries is a cost-effective means to improve the sustainability of both cities, particularly during periods of shrinking state and federal budgets (Bailey and Elliott 2009; McKinley 2008; Wyatt 2011). The PAIRS methodology is therefore useful not only in identifying sustainability initiatives which can be effectively leveraged, ${ }^{1}$ but also in identifying areas where reciprocity across one or multiple sectors can develop new initiatives which are economically beneficial for both cities. ${ }^{2}$

Partnership assessment for intra-regional sustainability model (PAIRS)

The PAIRS model has two aspects: (1) the metric, which identifies common resources and knowledge that can be leveraged to address common sustainability goals; and (2) the assessment, which examines the potential for local administrative collaborations as well as citizen interest in, and acceptance of, a PAIRS program or policy. The sustainability initiatives discussed in both aspects of PAIRS aim to address development that meets the needs of the present without compromising the ability of future generations to meet their own needs. The first goal of this paper was to quantitatively measure the communal reciprocity potential across these sectors within a local sustainability framework. The second goal was to investigate the differing demographic and psychological predictors of PAIRS policies (e.g., sharing common natural resources versus financial resources). Citizen assessment is a critical secondary goal in the form of policy acceptability, success, and program implementation (Gärling and Loukopoulos 2007; Schade and Schlag 2003; Vieira et al. 2007).

To identify synergies in municipal sustainability, PAIRS compiles data across five sectors to identify cooperative policies and practices of mutual benefit to potential partner cities and towns. The five sectors addressed are as follows: (1) water infrastructure and management, (2) energy systems, (3) food supply and agriculture, (4) recycling and waste, and (5) socio-geographic compatibility. Separate sustainability definitions for each of the five sectors set tangible goals for improvement. The definitions applied in this study were as follows:

- Water: Successful management of available water resources to meet the needs of human use and the natural environment in the present and future.

- Energy: A reduction in both pollutant emissions and reliance upon fossil fuel resources.

- Food and Agriculture: Production of sufficient and diverse foodstuffs to meet the regional human needs using non-damaging farming techniques.

\footnotetext{
1 An example of leveraging would be the expansion of an advanced recycling program implemented by one city to meet the additional demand of a neighboring community.

2 An example of a new initiative through reciprocity could be the pairing of farm waste and biofuel. If the transit authority of a city is importing biofuel for a bus fleet, they could turn to a neighboring community with large amounts of agricultural waste to produce biofuel locally. The transit authority would save money on fuel, and the farmers would have their waste removed at reduced cost.
} 
Table 1 Potential synergies used in the PAIRS metric

\begin{tabular}{llllll}
\hline $\begin{array}{l}\text { Potential } \\
\text { synergies }\end{array}$ & $\begin{array}{l}\text { Water } \\
\text { Water sharing, knowledge } \\
\text { of conservation, } \\
\text { infrastructure } \\
\text { development }(\%)\end{array}$ & $\begin{array}{l}\text { Energy } \\
\text { Conservation techniques, } \\
\text { infrastructure, utilization } \\
\text { of biofuel feedstocks }(\%)\end{array}$ & $\begin{array}{l}\text { Food and agriculture } \\
\text { farming techniques, local } \\
\text { food production and } \\
\text { consumption }(\%)\end{array}$ & $\begin{array}{l}\text { Sociographic } \\
\text { Public health, } \\
\text { environmental } \\
\text { stewardship (\%) }\end{array}$ & $\begin{array}{l}\text { Waste } \\
\text { Collection and } \\
\text { recycling } \\
\text { programs, waste } \\
\text { avoidance }(\%)\end{array}$ \\
\hline $\begin{array}{l}\text { Environmental } \\
\text { Economic }\end{array}$ & 45 & 50 & 25 & 12 & 17 \\
$\begin{array}{c}\text { Environmental } \\
\text { and economic }\end{array}$ & 33 & 12 & 25 & 25 & 17 \\
Social & 11 & 38 & 12 & 50 & 33 \\
\hline
\end{tabular}

- Recycling and Waste: Reduction in landfill accumulation through reuse, repurposing, and recycling.

- Socio-geographic Compatibility: A healthy and diverse living and economic environment with sufficient access to natural space and locally managed resources.

Rosen field identifies transdisciplinary research as the result of interdisciplinary scientists creating a shared conceptual framework that integrates and moves beyond discipline-specific theories, concepts, and approaches (Rosenfield 1992). The PAIRS model exemplifies this approach by developing a novel framework that spans sectors (e.g., water, waste, energy) familiar to the individual researchers and addresses a spanning notion that collaboration and partnership can improve sustainability as a social, economic, and environmental program and goal.

\section{Methods}

The potential for a new regional partnership paradigm is assessed using both a metric and a survey instrument. The metric is composed of 37 questions that address five public sectors with regional impact. The metric is intended for municipal planners or committees developing sustainability action plans to identify the partnerships with neighboring communities that could produce the greatest benefit. The survey instrument would also gauge the acceptability and potential for participation in theLEED certified or lowenergy buildings account community for a particular initiative or policy identified by the metric. Some questions from the metric will be included in this text to illustrate specific features of the questions, while the complete metric can be found in the Appendix. Within each of the five sectors, the questions address social, environmental, and economic issues of sustainability through quantifiable indicators, presence of best-practice techniques, availability and scarcity of natural resources, and the available knowledge base of previously implemented sustainability initiatives. The objective of the PAIRS metric was to identify synergies between communities which address different aspects of sustainability. Some of the potential synergies of each sector are presented below. Table 1 also presents a quantitative analysis of the areas of sustainability addressed by the questions within each subsection.

The PAIRS citizen assessment includes both independent and dependent variables (DV) measuring some common theoretical variables to establish a baseline, and nine variables specific to the intra-regional resource sharing framework suggested. One variable evaluated an individual's willingness to support a sister city policy for sustainability, while the other eight measured support specifically for sharing natural resources, educational resources, land space resources, or financial resources. Four of these evaluated a propensity for sharing with no guarantee of reciprocity, while four considered a mutual sharing arrangement.

\section{PAIRS metric scoring and weighting}

The total cooperative sustainability metric is the weighted sum of the identified potential impacts within each sector. Three questions determine the relative weighting by evaluating the economic importance, future risk, and geographic compatibility of partnerships within each sector. Several general questions address the social and political amicability of a partnership between the two communities. The formula for calculating the cooperative sustainability metric (CSM) is expressed in Eq. 2, where $i$ represent each of the five economic sectors.

$\mathrm{CSM}=\sum_{i=1}^{5}(\text { Sector Sustainability })_{i}+$ General Amicability

The disparity in available data for quantifiable indicators determined that a normalization approach would be best. With responses to each question worth between 0 and 3 points, qualitative indicators can be evaluated alongside more precise quantitative measures. Three points are given to responses which indicated both a high degree of existing 
sustainability and a large potential for improvement. Two points were given to answers which indicated a moderate to low existing sustainability but a large potential for improvement. One point was given for responses indicating a high degree of existing sustainability with little to no foreseeable future improvement. No points were awarded to responses indicating both a low existing sustainability and/or little expected improvement.

Each question is evaluated three times, once for each city independently, and once treating both cities as a single larger entity. The values assigned to the response of each individual city is averaged and used to normalize the combined city response. Values $>1$ indicates that a combination or partnership of the cities demonstrates a greater potential for improved sustainability. The responses to the questions of each sector are normalized and weighted according to Eq. 2.

Sector Sustainability $=\frac{\max \left(\text { City }_{\mathrm{i}}, \text { Combined }\right)}{\frac{1}{n} \sum_{i=1}^{n} \text { City }_{i}} \times W_{f}$

In Eq. 2, the variables $n$ and $W_{f}$ represent the number of cities being compared and the sector weighting factor, respectively. The number of cities is nominally 2 , but multicity partnerships are feasible as well. The relative a. Infrastructure is physically or virtually connected

b. Both cities currently use $>90 \%$ of their water allotment

c. Agricultural water is priced higher than residential/ urban pricing

PAIRS metric question types

After the three true/false questions, each section has five multiple choice questions with responses given $0-3$ points each. The multiple choice questions can be grouped into four types: quantitative, best practices, need and capability, and risk and preparation. ${ }^{3}$ Quantitative questions utilize commonly recorded metrics and create distinct thresholds for what is highly, moderately, minimally, and not sustainable by comparing values to national averages or best-practice figures. The following is an example of a quantitative question concerning the energy sector, specifically new building construction. The specific synergy being addressed is a knowledgeable local construction workforce with experience in building low-energy homes and offices. Construction of low-energy buildings not only considers reducing the energy consumption of the new building itself, but also that of the community as less efficient existing buildings are retrofitted.

" LEED certified or low-energy buildings account for of new building construction.

\section{a. $\quad 50-100 \%$ (3pts) b. $20-50 \%$ (2pts)}

importance of each sector is weighted by a factor which evaluates the importance of each sector to the cities in question. Each section of the cooperative sustainability metric begins with three true/false questions, a, b, and c, to determine the weighting factor for each sector as = $1+3 \times$ (\# of true answers to $\mathrm{a}, \mathrm{b}$, and $\mathrm{c}$ ). As such, the weighting factor of each sector can vary from 1 to 10 . The following examples are from the water portion of the metric. The first question identifies the potential for water sharing between the two cities construed in terms of enabling conservation practices to transfer excess water during droughts. The second question highlights a need for additional water conservation and a susceptibility to c. $5-20 \%(1 p t)$ d. $0-5 \%$ (Opts)

The impacts of many sustainable practices are not directly reflected in quantitative indicators. The social or environmental benefit may be difficult to quantify, or multiple sustainable practices may have overlapping impacts that cannot be distinguished. Indicators may be used to measure the aggregate sum of these practices. In some instances, a simple tally of the known best practices provides an indirect measure of impact. Some practices may be easier to implement, and others may have a greater impact, but ambitious sustainability goals require a holistic approach. The following is an example of a question from the PAIRS metric which tallies the number of water conservation practices applied within a community.

॥ Community policies encourage/enforce ___ of the following best practices.

*Groundwater monitoring, surface water monitoring, alternative irrigation techniques (drip), reliable water allotment (farmers get what they pay for), promotion/encouragement of non-intensive crop selection, urban xeriscaping, residential water efficiency measures (low-flow toilets/showers)
a. $\quad>4$ (3pts)
b. 3 (2pts)
c. $1-2(1 p t)$
d. None (Opts)

drought. The third question indicates a potential economic benefit in which urban water conservation could be sold for profit to nearby agriculture areas.

\footnotetext{
3 such as those for water use, energy use, or new building construction.
} 
A typical evaluation of this question with both an urban and agricultural city might go as follows. The urban area may specify building codes which mandate low-flow showers and toilets and offer incentives for low water intensity landscaping. The city would score one point for their two sustainable practices. A nearby agricultural city monitors surface water runoff and subsidizes drip irrigation installations would also score one point on this question. Treating both cities as a single entity, there would be four best practices in use, and the combined score would be three points. Applying the formula of Eq. 2 to just this single question would arrive at a value of 3 , indicating a strong potential for mutual benefit. Both cities have knowledge and experience to share. The agricultural city could adopt the building codes of the urban city and participate in the xeriscaping program. Likewise, the urban city could monitor surface water runoff and support the installation of drip irrigation. These best practices and need and capability questions often identify a potential partnership for knowledge sharing or matching a resource and an application; further examples abound. ${ }^{4}$

Some best practices, such as drip irrigation, may not apply to urban cities, but through partnerships with nearby agricultural regions, it may be an effective way to improve regional sustainability while having an economic benefit of greater crop yields for local produce. These best practices and need and capability questions often identify a potential partnership for knowledge sharing or matching a resource and an application. Urban cities generate vast quantities of compostable food waste but lack the application for compost. Meanwhile, farmers are spending ever more on fertilizers due to rising energy costs for ammonia production, which could be offset by a supply of compost from an urban sister city. The reciprocal trade of farm waste conversion to biofuel production completes the cycle with urban transit fleets often utilizing this local renewable fuel feedstock. The practices taken individually may benefit only one of the participating cities at the expense of the partner. A cross-sectorial analysis such as this example, which connects the energy and transportation sector with food and agriculture, demonstrates the mutual benefit from an urban-rural partnership.

\footnotetext{
${ }_{4}^{4}$ Urban cities generate vast quantities of compostable food waste but lack the application for compost. Meanwhile, farmers are spending ever more on fertilizers due to rising energy costs for ammonia production, which could be the offset by a supply of compost from an urban sister city. The reciprocal trade of farm waste conversion to biofuel production completes the cycle with urban transit fleets often utilizing this local renewable fuel feedstock. The practices taken individually may benefit only one of the participating cities at the expense of the partner. A cross-sectorial analysis such as this example connecting the energy and transportation sector with food and agriculture demonstrates the mutual benefit from an urban-rural partnership.
}

The multiple choice questions in the PAIRS metric identify specific areas of reciprocity and mutual benefit which could occur between two cities. When either the resource or application is missing from a single city, the score is low. When two cities match a resource and application, the combined score is higher. The normalization technique of Eq. 2 balances the numeric impact of each question on the evaluation of the total PAIRS metric. Each question that uncovers a possible collaboration between two cities increases the total PAIRS metric score.

\section{PAIRS assessment criteria}

Assessment of public acceptability of the PAIRS metric includes psychological, demographic, and contextual independent variables. Psychological variables include commonly investigated values within Schwartz's Value Theory, or the Value-Belief-Norm Theory (Stern 2000). The variables, listed from the most abstract to the most specific, include selftranscendence (e.g., care for others, peace, justice), enhancement (e.g., care for ego, accomplishments), biospheric (e.g., care for earth), traditionalism (e.g., respecting elders), and openness to change (e.g., curiosity, variety in life), as well as environmental concern and personal norm to protect the environment (e.g., feeling a moral environmental obligation). Several previous studies have found that biospheric and selftranscendent values predict environmental policy support (Stern et al. 1993; Karp 1996; Schultz and Zelenzy 1998; Milfont 2003; Poortinga et al. 2004). Several variables that are specific to sharing resources and supporting policy where also included: climate change risk perception, perceived social capital, self-reported political participation, and a Commons Dilemma variable that measures how much an individual trusts the citizens of their own city or another city to share resources in a period scarcity.

Finally, common demographic variables were included and hypothesized to follow previously determined patterns (Stern et al. 1993): Younger Democratic women would be more likely to vote for a PAIRS policy. Contextual variables included home ownership and years of local residence. Individuals with a longer history of ownership within the community were expected to have a greater interest in the long-term success and sustainable growth of the community, and thus support reciprocal sharing initiatives to a greater extent than a transient rental tenant.

\section{Results}

PAIRS metric analysis

The PAIRS metric can be applied to specific cities to highlight areas of mutual sustainability benefits. To establish a 
Table 2 Archetypal cities for pairwise analysis with PAIRS metric

\begin{tabular}{|c|c|c|c|}
\hline$\#$ & Size & $\begin{array}{l}\text { Approximate Southern } \\
\text { California City }\end{array}$ & Description \\
\hline 1 & Large & Santa Monica & $\begin{array}{l}\text { History of sustainability/ } \\
\text { moderate growth }\end{array}$ \\
\hline 2 & Large & San Bernardino & $\begin{array}{l}\text { Little sustainability/high } \\
\text { growth }\end{array}$ \\
\hline 3 & Large & Los Angeles & $\begin{array}{l}\text { Moderate sustainability/ } \\
\text { moderate growth }\end{array}$ \\
\hline 4 & Medium & City of Industry & Mostly industry \\
\hline 5 & Medium & Laguna Beach & Mostly retail \\
\hline 6 & Medium & Oxnard & Mostly agricultural \\
\hline 7 & Medium & Irvine & $\begin{array}{l}\text { Mostly commercial/ } \\
\text { residential }\end{array}$ \\
\hline 8 & Small & Yorba Linda & Suburban \\
\hline 9 & Small & Temecula & Agricultural \\
\hline 10 & Small & Big Bear Lake & Mostly rural/open space \\
\hline
\end{tabular}

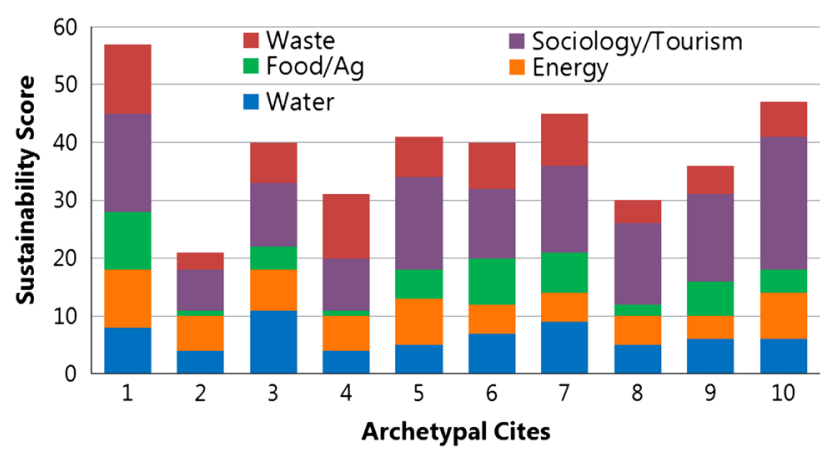

Fig. 1 Existing sustainability by sector for 10 archetypal cities of pairwise analysis

baseline and evaluate the effectiveness of the PAIRS metric, a pairwise analysis was conducted with 10 southern California cities listed in Table 2 . These cities were initially selected due to the amount of publically available data on local resources and sustainability practices. However, insufficient data existed in the public domain to complete the PAIRS metric analysis. Proxy data and regional averages were applied to fill data gaps. Due to the extent of proxy data utilized, the resulting conclusions cannot be supported for these specific city combinations, but they do represent a range of archetypal cities common to urban areas in the United States and around the world. The distribution of existing sustainability for each city varied across all five sectors as shown in Fig. 1. The cities chosen varied widely in terms of scale, primary industry, and interest in sustainability. Natural factors such as propensity for drought, available natural resources, open land space, and

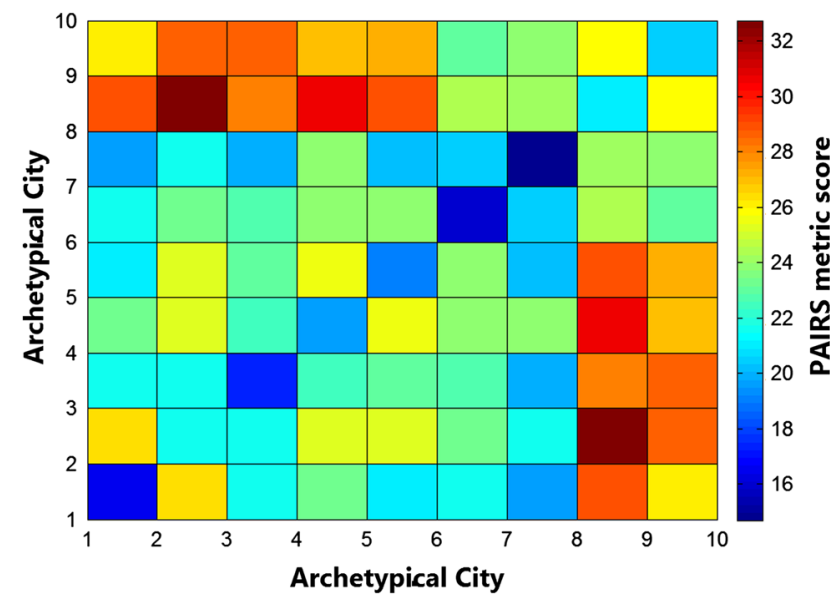

Fig. 2 Heat map distribution of pairwise analysis using PAIRS metric

distance from neighboring cities played a distinct role in the potential for synergistic partnerships. As many of these features can differ between cities of the same scale and industry, these 10 cities do not capture every possible scenario, but are useful in demonstrating the application of the PAIRS metric.

The pairwise analysis evaluated every possible combination of two cities from the list of 10 , including a partnership with an identical city. The heat map depicted in Fig. 2 shows the resulting score from the PAIRS metric. The amicability questions were omitted, as they pertain to attitudes of specific towns rather than our archetypal cities. Three important points may be drawn from Fig. 2. First, the results are symmetric across the diagonal, indicating a partnership between cities A and B is as promising as a partnership between cities B and A. Second, the region of high scores in the upper left and lower right indicates that partnerships between large cities and small towns are among the most beneficial. Third, the lowest score for each city lies on the diagonal, indicating a partnership with an identical city offers the least amount of mutual benefit.

Typical municipal sustainability strategies seek to group similar towns under the impression that a practice that benefits city A must be beneficial to all cities like city A (Rittel and Webber 1973). This analysis suggests substantially greater sustainable potential is achieved when the heterogeneous resources of two different cities are harnessed to support a common sustainability goal. The greatest mutual benefit occurs between agrarian and urban cities, mainly through the utilization of each other's waste streams. Urban centers often rely upon several regional hinterland communities to feed their populations, and any 


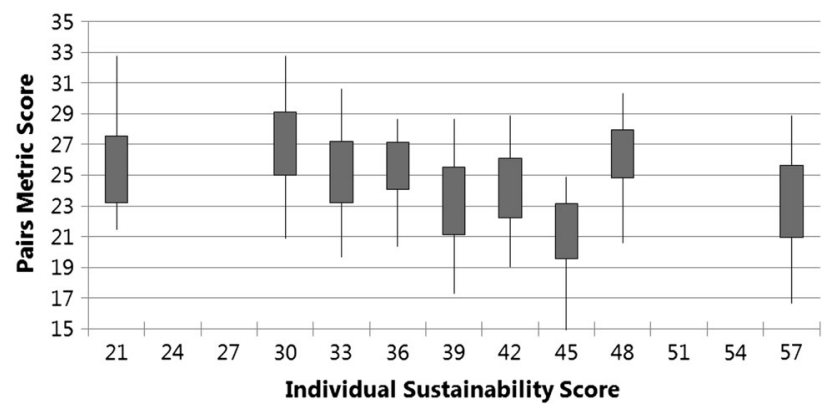

Fig. 3 Comparison of existing sustainability with PAIRS cooperative metric for potential improvement

improvement upon its rural food chain improves the sustainability of the urban center. This finding that municipal differences hold the greatest potential for mutual benefit is perhaps the most important deduction from this analysis of municipal partnerships.

Figure 3 compares the existing sustainability of each archetypical city to the range of potential sustainability improvements through cooperation with each of the other nine archetypical cities as measured with the PAIRS metric. One would expect a city with organized sustainability objectives and existing programs to demonstrate a much lower potential for improvement. These results confirm a slight negative trend in potential for improved sustainability versus existing sustainability. However, the negative trend is minimal for two reasons: (1) The highly organized city with a myriad of sustainability programs can dramatically improve the sustainability of a less organized neighbor (the PAIRS metric reflects the combined improvement of both cities), and (2) additional opportunities for sustainable development of the highly organized city would likely arise as the natural boundaries of resources and pool of knowledgeable individuals expands through a partnership.

Figures 4 and 5 present the pairwise analysis results for the water and waste subsections of the PAIRS metric. Figure 4 presents results from the water sector and demonstrates the diversity of the resulting scores. No discernible trends emerge, indicating that the water demands and resources of each city are unique. Opportunities for mutual benefit may present themselves between the most unlikely of pairings and may often support reciprocity of different sectoral partnerships. Water will remain a crucial component for sustainability, particularly within the arid southwest, and any potential resources must be evaluated. The

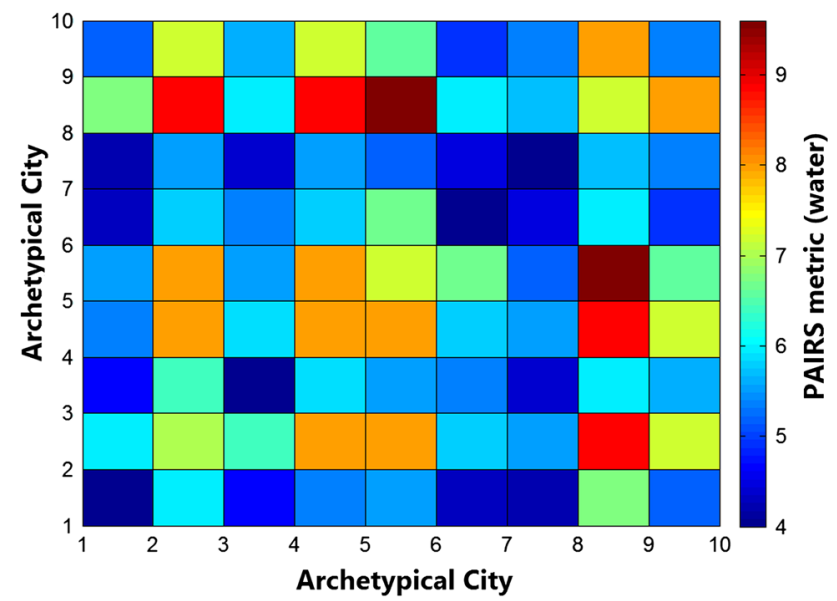

Fig. 4 Water sector heat map result of pairwise analysis using PAIRS metric

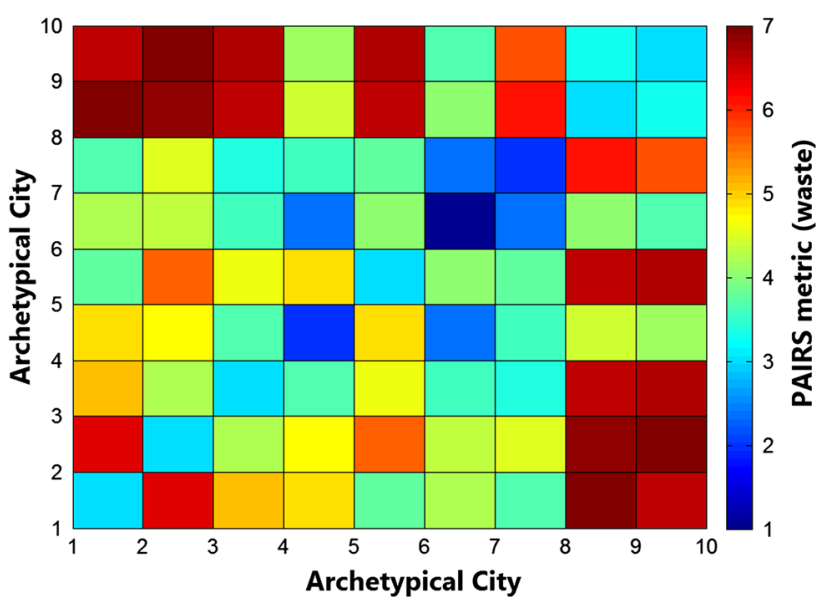

Fig. 5 Waste sector heat map result of pairwise analysis simulation

results from the waste sector strongly reflect those of the complete PAIRS metric in that small agrarian cities pair well with urban centers. This is in response to several sustainability practices which pair waste streams with an application. Composting of urban food waste can help meet the fertilizer needs of the rural farmers, while farming waste, cellulosic biomass, can be processed into biofuel for fleet vehicles such as urban mass transit. The potential for sustainability improvement is greatest in the waste category because not only is a resource matched to an application, but the waste stream from both cities is reduced through repurposing and recycling. 
Table 3 Predictors of sharing resources with and without reciprocity
$* p<1$ indicates marginal significance

$* * p<05$ indicates strong significance

\begin{tabular}{|c|c|c|c|c|c|c|c|c|}
\hline & \multicolumn{4}{|c|}{ Shared resource without reciprocity } & \multicolumn{4}{|c|}{ Shared resource with reciprocity } \\
\hline & Finances & Natural & $\begin{array}{l}\text { Land/ } \\
\text { space }\end{array}$ & Education & Finances & Natural & $\begin{array}{l}\text { Land/ } \\
\text { space }\end{array}$ & Education \\
\hline Self-transcendence & $.53 * *$ & $.24 *$ & $.34 * *$ & $.40 * *$ & $.57 * *$ & $.43 * *$ & $.38 * *$ & $.40 * *$ \\
\hline Biospheric & $-.25^{*}$ & & & & & & & \\
\hline $\begin{array}{l}\text { Personal norm to } \\
\text { environment }\end{array}$ & $.22 * *$ & $.24 *$ & & & & $.22 *$ & & \\
\hline Self-enhancement & & & $-.23 *$ & $-.42 * *$ & & $-.23 *$ & $-.30 * *$ & $-.30 * *$ \\
\hline Social capital & & & & & & $.19^{*}$ & & \\
\hline Commons trust & & & & & & $-.23 * *$ & & \\
\hline Education & & & & $-.21 *$ & & & & \\
\hline Income & & & & & $-.23 *$ & $-.19 *$ & & \\
\hline Homeowner & & & & & $.18^{*}$ & & & \\
\hline $\begin{array}{l}\text { Duration of } \\
\text { residence }\end{array}$ & & & & & $-.22 * *$ & & & \\
\hline Age & & $-.24 *$ & $-.22 *$ & & $.57 * *$ & & & \\
\hline
\end{tabular}

PAIRS community assessment

Reflective of the cities tested above, a survey was sent to Southern California voters via email three consecutive Mondays mornings from 7:00 a.m. to 10:00 a.m. PCT. Each "blast" included 5,000 randomly selected and distinct emails. Of those emailed, 145 responded and completed the survey. Sample demographic characteristics were similar to Los Angeles County and US Census statistics in all categories (gender, age, race, and income), aside from education and political affiliation. Quite a few more respondents had a bachelor's degree or higher than in LA County and the USA. The sample had the same percent of Democrats as the USA $(\sim 51 \%)$, but far less than LA County ( $\sim 69 \%)$ and far fewer Republicans than both LA County and the US. The results of a logistic regression analysis are presented in Table 3. The use of odds ratios rather than predicted probabilities from logistic regression outputs not only provided a robust method that is invariant to sample design, but also allowed for ease in interpretation. Results are presented in terms of beta values, ranging from +1 to -1 , where positive values reflect a positive correlation, while negative values reflect an inverse correlation. Among independent variables, while many significant correlations were revealed, none were so strong as to raise concern of multi-collinearity.

For general policy support, being educated, a Democrat, and having strong environmental norms and personal norms to protect the environment predicted policy support, whereas being older negatively predicted support. Moreover, across outcomes, the psychological variables that most consistently predicted acceptance of reciprocal or non-reciprocal sharing policies were self-transcendence and personal norm to protect the environment. Conversely, self-enhancement negatively predicted policy support on several occasions. Interestingly, a combination of demographic and psychological variables predicted supporting the policy with the expectation of reciprocity, whereas predominantly psychological values and norms predicted supporting the policy without the expectation of reciprocity. In terms of variables that predicted support for sharing educational, land, natural, and financial resources with another city, with or without the expectation of reciprocity, the following results were determined.

Psychological variables unique to the PAIRS framework were particularly relevant in predicting sharing natural resources with the expectation of reciprocity. Specifically, while having little trust that another city would return the favor in a Commons Dilemma negatively predicted support, perceived social capital of one's own city positively predicted support.

Four additional results were particularly compelling. First, while homeownership positively predicted sharing financial resources with the expectation of reciprocity, length of residence negatively predicted this same dependent variable. As both independent variables speak to a sense of connection with the city, these results may be due to the respondents' focus on their own personal economic 
welfare (within their "owned land") rather than the welfare of the city's land.

Second, being highly educated negatively predicted support for sharing educational resources when no reciprocity was expected. Third, having a higher income negatively predicted support for sharing financial resources when no reciprocity was expected. Finally, counter to previous research (e.g., de Groot and Steg 2008), biospheric values negatively predicted support for sharing financial resources when no reciprocity was expected. This result may be a reflection of the fine line between selftranscendent and biospheric values found in previous research (De Groot and Steg 2008); here, those reporting high biospheric values may be more focused on the environment, than people, and therefore may distrust the idea of sharing money for sustainability or "economic" sustainability.

\section{Conclusion}

This section offers a discussion of main findings of the present study, limitations of the PAIRS tool, challenges foreseen for local municipalities to adopt PAIRS as a planning tool, and policy implications that can be drawn from this research.

Analysis of the PAIRS model produced three central findings. First, the output from the model simulations suggests that pairing cities with similar major attributes produces at best only minimal improvements in either city's sustainability or overall sustainability. Second, pairings that yielded the greatest improvements in sustainability were those that matched two cities with a significant disparity in size, existing level of sustainability, growth, or community type. Third, matching two cities with differential characteristics resulted in substantial increases in levels of sustainability in both communities. In short, the results from the simulations points to the idea that it is the differences between neighboring cities which make for the greatest partnerships.

However, the PAIRS model also features several limitations which bear careful consideration. PAIRS is useful in identifying local partners and potential areas of partnership, but cannot provide specific sustainability initiatives or direct measurements of their value. It can only identify areas where local resources are strained or underutilized and suggest that certain partnerships may be mutually beneficial, or that certain partnerships could span different resource sectors.

The primary challenge of employing PAIRS as a planning tool is the large amount of data required to complete the analysis for all potential municipal partnerships. City planners attempting to complete the PAIRS metric may very well encounter difficulties retrieving requisite data on their own city, much less that of a potential sister city. Over the course of our study, we distributed a Request for Information (RFI) which covered all of the data necessary to complete the survey to over 250 cities and counties within the states of Arizona, California, Colorado, Florida, Oregon, and Washington. The response rate was expectedly low, $3.5 \%$, as was the completion rate, $10 \%$. The low completion rate typically covered important demographic and geographic criteria that would support a majority of the survey questions.

The additional sustainability specific questions-for instance, "How many local farmers markets are open each week?", would require specific research by the entity applying PAIRS. This was the approach undertaken in this study to fill in what gaps we could for our Southern California test cities. The data were often spread among different divisions or departments of the same municipal government making retrieval difficult. Additional barriers in the utilization of PAIRS may include a lack of financial resources, personnel, or time during the planning stage, and hesitant leadership which may not perceive the value of PAIRS or even ideological opposition to pursuing sustainability objectives. Indeed, respondents to the psychological survey identified similar barriers to implementing a sister city policy, including financial limitations, bureaucratic red tape, political stalemates, and cultural differences. Related, while the citizen assessment revealed what resources a particular LA county citizen profile is willing to share, hard infrastructure and resources metrics translate more easily between cities and cultures than psychological attitudes. As such, the psychological results of this study are geographically bound to LA County, and any future similar assessment, to its respective sample population. Indeed, psychological profiles are only introduced by this paper to demonstrate their potential use to administrators interested in garnering local public support for the PAIRS policy.

These challenges and limitations were identified during the application of PAIRS to southern California cities. Similar or different challenges may exist when applied elsewhere. In China, a study assessing the sustainability of 30 provincial capitals included only two environmental quality indices, air quality and noise pollution, due to limited data availability (Fan and Qi 2010). In Australia, sustainability metrics and population data are more readily accessible from the Australian Bureau of Agricultural and Resource Economics and Sciences, but researchers still find themselves hampered by a lack of relevant data for 
regional-level sustainability analyses (Graymore et al. 2008).

PAIRS is a data-driven algorithm, and without access to sufficient data on the existing resources, industries, and sustainable initiatives of both cities, the results can contain errors. The normalization technique eliminates bias from errors on any particular question, but widespread estimations should be avoided. Publicly available data are likely insufficient to conduct an accurate assessment of the potential for synergistic cooperation on sustainability. Thus, it is recommended that any future researchers interested in implementing this methodology either be employed within or be closely partnered with a city. Without such a partnership in place, one will likely face a similar combination of the barriers discussed above.

The PAIRS methodology provides cities with a framework to comparatively evaluate different sustainability initiatives and regional partnerships. The model holds clear implications for the development of future sustainability policy at the municipal level. Here, we identify five benefits of applying this technique which may assist local government administrators and urban planners during the outlining or development of sustainability plans.

1. This tool can help local governments promote and tailor sustainable activities to meet the needs and wants of residents. By applying the PAIRS metric and conducting an assessment survey, municipalities can gain a sense of what kinds of sustainability initiatives are viable and effective and which are likely to earn broad support or meet resistance. This knowledge can enable staff to effectively communicate environmentally focused projects to residents.

2. PAIRS can help cities identify highly effective and readily implemented practices which can leverage local resources or sustainability capital between two cities and even lead them full circle back to more traditional sister city exchanges of informal cultural capital.

3. Jointly pursuing sustainable development, as this method suggests, helps actors to effectively share the burden of developing and implementing new sustainable strategies. By utilizing PAIRS to locate a partner city to leverage existing resources and reap benefits not currently enjoyed, both cities can address their needs in a way that might be more cost-effective than pursuing them in isolation.

4. The PAIRS metric does not show bias toward any single sector and thus could encourage reciprocity in different sectors. One partner might seek a collaboration to boost its sustainable water supply and offer a reciprocal exchange of compostable waste with a partner city. Thus, the balance of sustainable improvement is equal for both participating cities.

5. The PAIRS metric can be utilized over time to measure improvement and identify new areas in which to address sustainability as circumstances and needs evolve.

PAIRS represents an important innovation in sustainability science and an achievement in transdisciplinary research-the type of research needed to remediate global problems (Stokols 2006). Unlike the more common interdisciplinary approach, which looks to short-term problemsolving and tends to have minimal impact on theory and the ever changing state of society, this research draws on easily identifiable theoretical frameworks to provide a comprehensive analysis that goes beyond any singular discipline's approach (Rosenfield 1992). Using the sister city model to foster cooperation among cities, a team of researchers from different disciplines produced a data-driven mathematical tool that cities can use to evaluate the prospects for improving sustainability practices by leveraging existing resources and establishing synergistic partnerships along key sustainability dimensions with neighboring cities. This project will serve not only to inspire more scholarly work on exploring new ways to increase sustainability in urban and rural settings, but also to implement changes in the manner in which sustainability objectives are pursued at the municipal level.

Acknowledgments The authors wish to acknowledge the University of California Irvine Sustainability Science Team Initiative, its Director, Professor Michael Prather, and Assistant Director, Susan Coons for their academic and financial support.

Open Access This article is distributed under the terms of the Creative Commons Attribution License which permits any use, distribution, and reproduction in any medium, provided the original author(s) and the source are credited. 
Appendix: Pairs: partnership assessment for intraregional sustainability

Water

Weighting factor questions: $W_{F}=1+3 \times$ (\# of yes answers to $a, b$, and $c$ )

a. Infrastructure is physically or virtually connected (Opens possibility of water sharing)

b. Both cities currently use $>90 \%$ of their water allotment (Demonstrates need for water conservation)

c. Agricultural water is priced higher than residential/urban pricing (Demonstrates potential economic gain)

1. Regional water consumption per capita* is __ and the aggregate is the sustainable threshold + .

*Water use will be compared to state level average uses for the majority land use type (urban, farming, mixed)

† Sustainable threshold includes surface allotment as appropriated by a water management agency \& renewable ground water.
a. Below average, below
(3pts)
c. Above average, equal to or above
(1pt)
b. Above average, below
(2pts)
d. Near or below average, equal to or above
(Opts)

2. Water conservation projects* are saving or could save $\%$ of water use beyond sustainable threshold + without substantially impacting agricultural production or residential water costs *Use expected savings from best practices including: reclaimed water, xeriscaping, watering schedules, and drip irrigation † Sustainable threshold includes surface allotment as appropriated by a water management agency \& renewable ground water.
a. $>25 \%$
c. $0-10 \%$
(1pt)
b. $10-25 \%$
(2pts)
d. $<0 \%$
(Opts)

3. Community policies encourage widespread deployment of of the following best practices. Groundwater monitoring, Surface water monitoring, alternative irrigation techniques (drip), reliable water allotment (farmers get what they pay for), promotion/encouragement of non-intensive crop selection, Urban xeriscaping, Residential water efficiency measures (low-flow toilets/showers) *In the combined case only 1 town must have the practice to count*
a. $>4$ (3pts)
c. $1-2$
(1pt)
b. 3 (2pts)
d. none
(Opts)

4. The city/region's current and future risk* of water shortages is and the city/region plans or policiest for potential water shortage scenarios.*Future risk is assessed by expected a)population growth, b) agricultural growth, c)reduced precipitation due to climate change, d) groundwater depletion from unsustainable practices.

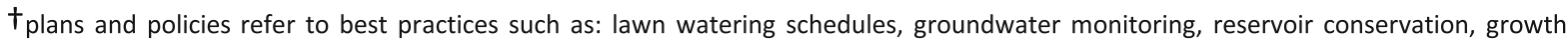
arrestment, tiered or alternative progressive water pricing
a. Low, plans and policies
(3pts) c. Low, no
(1pt)
b. High, plans and policies
(2pts)
d. High, no plans or policies
(Opts)

5. The City/Region need* and capability to expand current water facilities $\neq$.

*Need refers to a past flood history, water treatment facility shortage, poor water quality, growing population or commerce,

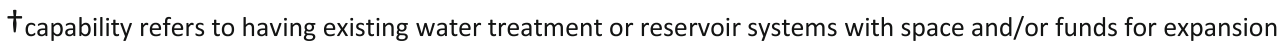

ҒWater facilities include water treatment facilities, potable reservoir systems, and flood control reservoirs
a. Does, possesses
(3pts)
c. Does not, doesn't possess
b. Does not, possesses
(2pts)
d. Does, doesn't possess
(1pt)
(Opts) 
Energy/transportation

Weighting factor questions: $W_{F}=1+3 \times$ (\# of yes answers to $a, b$, and $c$ )

a. Infrastructure is physically or virtually connected (Opens possibility of energy sharing)

b. Renewable penetration is below state RPS (<33\% CA ) (Demonstrates need for renewable energy projects)

c. Energy demand is expected to grow $>10 \%$ by 2020 (Demonstrates need for energy projects/demand measures)

1. Mass transit use exceeds___ \%, connect with regional transportation options, and ridership match local demographics. * Mass transit: light rail, bus, carpool lanes, van share, rideshare programs
a. $10 \%$, Does, Does
(3pts)
c. $10 \%$, Does not, Does
(1pt)
b. $5 \%$, Does, Does
(2pts)
d. $<5 \%$ or Doesn't match demographics
(Opts)

2. LEED certified or low-energy buildings account for
a. $50-100 \%$
(3pts)
c. $5-20 \%$
b. $20-50 \%$
(2pts)
d. $0-5 \%$
(1pt)
(Opts) of new building construction.

3. Local renewable energy potential is of total energy consumption; Local renewable energy production is of total energy consumption.
a. $>18 \%,>50 \%$
(3pts)
c. $>18 \%,<50 \%$
(1pt)
b. $<18 \%,>50 \%$
(2pts)
d. $<18 \%,<50 \%$
(Opts)

4. Local renewable energy production is i) demand response programs, ii) installation of grid supportive energy storage devices, iii) smart grid technology
a. Supported by i), ii) \& iii)
(3pts)
c. Not supported by i), ii) or iii)
(1pt)
b. Supported by i), ii) or iii)
(2pts)
d. Not present and not planned for
(Opts)

5. Local biofuel feed stocks* are available and utilized.

*biofuel feed stocks include: water treatment digester gas, landfill gas, animal waste, cellulosic waste, and food processing waste.
a. Presently, under
(3pts)
c. Occasionally, fully
(1pt)
b. Uncollected/untreated, under
(2pts)
d. Scarcely, under
(Opts)

Food and agriculture

Weighting factor questions: $W_{F}=1+3 \times$ (\# of yes answers to $a, b$, and $c$ )
a. Agriculture accounts for more than $5 \%$ of local employment of 1 or more of the cities
b. More than $10 \%$ of local agricultural production comes from small farms $(<\$ 250,000 /$ year $)$
c. Separated by less than 100 miles (demonstrates feasibility of local scale agriculture)

1. Agriculture production is $\%$ of local food consumption. *measured by $\$ /$ person
a. $100-150$ (3pts)
c. $50-100$
(1pt)
b. $150-200$ (2pts)
d. $0-50$ or $200+$
(Opts)

2. Residents host or produce for certified local farmers markets or harvest festivals.
a. $>10$
(3pts)
c. 2-5
(1pt)
b. $6-10$
(2pts)
d. $0-1$
(Opts)

3. Urban farming \& small family farms are supported locally by _ agencies/non-profits/co-ops/grants.
a. All of the above
(3pts)
c. External agencies/groups only
(1pt)
b. Some agency/non-profit/co-op
(2pts)
d. None of the above
(Opts) 
4. local restaurant association and/or grocers certification for sustainable practices* .

*Sustainable practices include: local purchasing (<100mile), organic produce, packaging, free-range animal, and sustainable fisheries
a. Either, specify and enforce (3pts)
c. Either, offer \& promote
(1pt)
b. Both, offer \& promote
(2pts)
d. Neither, offer or promote (Opts)

5. Local agencies (farm co-op or water board) i) crop selection for bio-diversity and reduced water intensity, ii) organic farming practices.
a. Incentivize and promote i) \& ii)
(3pts)
c. Educate or encourage i) or ii)
(1pt)
b. Incentivize and promote i) or ii)
d. Do not facilitate i) or ii)
(Opts)

Sociogeographic compatibility

Weighting factor questions: $W_{F}=1+3 x$ (\# of yes answers to $a, b$, and $c$ )

a. Local attractions/parks are under-utilized

b. Separated by less than 100 miles

c. Separated by less than 20 miles and a significant portion of one cities retail is purchased externally.

1. Boundaries include or abut acres of National/Stat/Regional/Local park space per capita.
a. $2+$
(3pts)
c. $.1-.5$
(1pt)
b. $.5-2$
(2pts)
d. $0-.1$
(Opts)

2. Natural feature tourism (beaches, mts, rivers, parks) accounts for $>50 \% /<50 \%$ of revenue and is/is not actively maintained/preserved.
a. $>50 \%$, is
c $>50 \%$, is not
b. $<50 \%$, is
(2pts)
d. $<50 \%$, is not

3. Residents would consider which of the following most important for new public policies directed at sustainability
a. Environment and public health
b. Modernization of regional infrastructure (water, transportation, recycling)
c. Implementation of best-practices type policies for industry/government
d. Government interference and visual aesthetics from property
(Opts)

4. The number of local sustainability initiatives that have been discussed or implemented.
a. $10+$
(3pts)
c. 2-5
(1pt)
b. $5-10$
(2pts)
d. $0-2$
(Opts)

5. The number of local educational programs for students/young adults/community leaders on sustainable practices
a. 10+
(3pts)
c. 2-5
(1pt)
b. 5-10
(2pts)
d. $0-2$
(Opts) 
Waste management and recycling

Weighting factor questions: $W_{F}=1+3 \times$ (\# of yes answers to $a, b$, and $c$ )

a. One or both cities currently have no recycling or bio/green waste programs

b. Municipal waste hauled $>25$ miles on average

c. One or both cities include/abut an ecologically sensitive area (coastal/tidal, migratory, etc.)

1. Collection and processing of recyclable materials includes
a. Current best practices
(3pts)
c. Glass and aluminum only
(1pt)
b. Glass, aluminum and some plastics/paper (2pts)
d. Recyclables are not collected
(Opts)

2. The portion of biomass waste (yard trimmings) generated that are collected is
a. $40+\%$
(3pts)
c. $5-15 \%$
(1pt)
b. $15-40 \%$
(2pts)
d. $0-5 \%$
(0pts)

3. Local policies encourage "paperless" office practices
a. Encourage and incentivize (3pts)
c. Educate only
(1pt)
b. Encourage and promote (2pts)
d. Do not support
(Opts)

4. City/municipal waste prevention is considered
a. Critical, and already implemented
(3pts)
c. Unimportant/impractical/costly
b. Important, but too costly
(2pts)
d. Never considered

(1pt)

(0pts)

5. Landfill waste is and serves
c. Local, the city/town
(3pts) c. Off-site, city + neighbors
(1pt)
a. Local, city + neighbors
(2pts)
d. Multiple locations/off-site, part of/only city (Opts)

Amicability questions: combined city/district questions

1. Are your two cities under similar jurisdiction in the following 4 areas: emergency management district, water management district, air quality management district, county governance.
a. In all four areas
(3pts)
c. In 1 area
(1pt)
b. In 2-3 areas
(2pts)
d. Not in any areas
(Opts)

2. The history of cooperation and mutual economic development is

a. Long and mutually beneficial

b. Beneficial to one city/region (3pts)

c. Unsuccessful

(2pts)

d. Never attempted or discussed (1pt)

(Opts)

3. Ideological and political preferences are
a. Strongly aligned
(3pts)
c. Different
(1pt)
b. Somewhat aligned (2pts)
d. Opposed
(Opts)

\section{References}

Bailey MN, Elliott DJ (2009) The US financial and economic crisis: where does it stand and where do we go from here? Initiative on business and public policy. The Brookings Institution, USA

Benfield K (2012) The limits of metropolitan planning organizations: the Atlantic cities com. http://www.theatlanticcities.com/poli tics/2012/04/limits-metropolitan-planning-organizations/1878/. 30 May 2013

Betsill MM (2001) Mitigating climate change in U.S. cities: opportunities and obstacles. Local Environ 6:393-406. doi:10. 1080/13549830120091699
Bulkeley H, Betsill MM (2003) Cities and climate change: urban sustainability and global environmental governance. Routledge Studies in Physical Geography and the Environment

Clarke N (2010) Town twinning in cold-war Britain: (dis)continuities in twentieth-century municipal internationalism. Contemp $\mathrm{Br}$ Hist 24:173-191. doi:10.1080/13619461003768272

Cremer RD, De Bruin A, DuPuis A (2001) International sister-cities: bridging the global-local divide. Am J Econ Sociol 60:377-401. doi:10.1111/1536-7150.00066

De Groot J, Steg L (2008) Value orientations to explain beliefs related to environmental significant behavior: how to measure egoistic, altruistic, and biospheric value orientations. Environ Behav 40:330-354. doi:10.1177/0013916506298797 
Dernbach JC (2000) Moving the climate change debate from models to proposed legislation: lessons from state experience. Environmental law reporter 30, 10,933. SSRN: http://ssrn.com/abstract= 1103064

Ewen S, Hebbert M (2007) European cities in a networked world during the long twentieth century. Environ Plan C Gov Pol 25:327-340. doi: $10.1068 / \mathrm{c} 0640$

Fan P, Qi J (2010) Assessing the sustainability of major cities in China. Sustain Sci 5:51-68. doi:10.1007/s11625-009-0096-y

Gärling T, Loukopoulos P (2007) Effectiveness, public acceptance, and political feasibility of coercive measures for reducing car traffic. In: Gärling Tommy, Steg Linda (eds) Threats to the quality of urban life from car traffic: problems, causes, and solutions. Elsevier, Amsterdam, pp 313-324

Graymore MLM, Sipe NG, Rickerson RE (2008) Regional sustainability: how useful are current tools of sustainability assessment at the regional scale? Ecol Econ 67:362-372

Großpietsch J (2009) More than food and folk music? Geographical perspectives on European town twinning. Geogr Compass 3:1281-1304. doi:10.1111/j.1749-8198.2009.00238.x

Großpietsch J (2010) The changing geographies of international municipal relations in Europe: a study of British-German town twinning partnerships. Loughborough University Institutional Repository. https://dspace.lboro.ac.uk/2134/8346

Hardin G (1968) The tragedy of the commons. Science 162:1243-1248. doi:10.1126/science.162.3859.1243

Jayne M, Hubbard P, Bell D (2011) Worlding a city: twinning and urban theory. City 15:25-41. doi:10.1080/13604813.2010. 511859

Kambuj A (2013) Climate action planning and policy in the city of Urbana. Proceedings from NEURUS-ICURD Workshop and Seminar, Urbana-Champaign

Karp DG (1996) Values and their effect on pro-environmental behavior. Environ Behav 28:111-133. doi:10.1177/00139165 96281006

McKinley $T$ (2008) Economic policies for growth and poverty reduction: PRSPs, neoliberal conditionalities and 'post-consensus' alternatives. IDS Bull 39:93-103. doi:10.1111/j.1759-5436. 2008.tb00450.x

Milfont T (2003) Time perspective and values: an exploratory study of their relations to environmental attitudes. J Environ Psychol 26:72-82. doi:10.1016/j.jenvp.2006.03.001

Papagaroufali E (2005) Town twinning in Greece: reconstructing local histories through transposal sensory-affective performances. Hist Anthropol 16:335-347. doi:10.1080/02757200500 219321
Payre R (2010) The importance of being connected. City networks and urban government: Lyon and Euro cities (1990-2005). Int J Urban Reg Res 34:260-280. doi:10.1111/j.1468-2427.2010. 00937.x

Poortinga W, Steg L, Vlek C (2004) Values, environmental concern and environmentally significant behavior: a study into household energy use. Environ Behav 36:70-93. doi:10.1177/001391650 3251466

Rittel HW, Webber MM (1973) Dilemmas in a general theory of planning. Policy Sci 4:155-169

Rosenfield PL (1992) The potential of transdisciplinary research for sustaining and extending linkages between the health and social sciences. Soc Sci Med 35:1343-1357

Satterthwaite D (2008) Cities' contribution to global warming: notes on the allocation of greenhouse gas emissions. Environ Urban 20:539-549. doi:10.1177/0956247808096127

Schade J, Schlag B (2003) Acceptability of urban transport pricing strategies. Trans Res 6:45-61. doi:10.1016/S1369-8478(02) 00046-3

Schultz PW, Zelenzy L (1998) Values and proenvironmental behavior: a five-country survey. J Cross Cult Psychol 29:540-558. doi: $10.1177 / 0022022198294003$

Stern PC (2000) Toward a coherent theory of environmentally significant behavior. J Soc Issue 56:407-424. doi:10.1111/00224537.00175

Stern N (2007) The economics of climate change: the stern review. Cambridge University Press, Cambridge, UK p 457 doi:10.1111/ j.1728-4457.2006.00153.x

Stern P, Dietz T, Kalof L (1993) Value orientations, gender, and environmental concern. Environ Behav 25:332-348

Stokols D (2006) Toward a science of transdisciplinary action research. Am J Community Psychol 38:63-77

Vieira J, Moura F, Viegas J (2007) Transport policy and environmental impacts: the importance of multi-instrumentality in policy integration. Trans Policy 14:421-432. doi:10.1016/j. tranpol.2007.04.007

Vion A (2002) Europe from the bottom up: town twinning in France during the cold war. Contemp Eur Hist 4:623-640. doi:10.1017/ S096077730200406X

Wyatt K (2011) State budget cuts decimate mental health services. The Washington Post.com March 2011. Associated press. http:// www.washingtonpost.com/wp-dyn/content/article/2011/03/09/ AR2011030900507.html. 9 Mar 2013

Zelinski W (1991) The twinning of the world sister cities in geographic and historical perspective. Ann Assoc Am Geogr 81:1-31. doi:10.1111/j.1467-8306.1991.tb01676.x 